faster and more completely than when appropriate eye fixations were not permitted. This tends to indicate that the role of eye fixation in the recall of spatially organized imagery is analogous to the role of eye fixation in perception.

\section{REFERENCES}

Bower, G. Mental imagery and associative learning. In L. Gregg (Ed.), Cognition in learning and memory. New York: Wiley, 1972 .

Hale, S. M., \& Simpson, H. M. Effects of eye movements on the rate of discovery and the vividness of visual images. Perception \& Psychophy sics, 1970, 9, 242-245.

Haslerud, G. M. Transfer, memory and creativity: After-learning as perceptual process. Minneapolis: University of Minnesota Press, 1972.

Hębb, D. O. Concerning imagery. Psychological Review, 1968, $75,466-477$.

Hindmarch, I. Eye movements and the perception of phenomenal causality. Psychologica Belgica, 1973, 13, 17-23. Kahneman, D. Attention and effort. Englewood Cliffs, New Jersey : Prentice-Hall, 1973.

Mackw orth, N. H. The wide-angle reflection eye camera for visual choice and pupil size. Perception \& Psychophysics, 1968, 3, 32-34.

Marks, D. F. Individual differences in the vividness of visual imagery and their effect on function. In P. Sheehan (Ed.), Function and nature of imagery. New York and London: Academic Press, 1972.

Marks, D. F. Visual imagery differences and eye movements in the recall of pictures. Perception \& Psychophysics, 1973, 14, 407-412.

Webster, R. G., \& Haslerud, G. M. Influence on extreme peripheral vision of attention to a visual or auditory task. Journal of Experimental Psychology, 1964, 68, 269-272.

Winer, B. J. Statistical principles in experimental design. New York: McGraw-Hill, 1967.

\section{NOTE}

1. Hall, D. C. Eye movements in scanning iconic imagery. In preparation, 1974.

(Received for publication February 4, 1974.)

\title{
Sexual arousal and physical aggression: The inhibiting influence of "cheesecake" and nudes
}

\author{
ROBERT A. BARON* \\ Purdue University, West Lafayette, Indiana 47907
}

\begin{abstract}
Male Ss participated in an experiment designed to investigate the hypothesis that mild levels of sexual arousal would serve to inhibit subsequent physical aggression. Consistent with this suggestion, Ss exposed to two types of erotic stimuli ("cheesecake" or nudes) directed shocks of significantly shorter duration to a confederate of the $\mathbf{E}$ than Ss exposed only to neutral pictures of scenery, furniture, and abstract art. An interpretation of these findings based on the suggestion that mild sexual arousal is pleasurable, and serves to induce considerable positive affect among Ss, was proposed.
\end{abstract}

It has frequently been contended that sexual and aggressive motives are intimately linked. For example, Freud (1933) noted that desires to hurt or be hurt by one's lover form a normal part of heterosexual relations. Similarly, Berne (1964) has suggested that the arousal of aggressive motives often serves to enhance sexual pleasure for both men and women. Empirical evidence for the existence of a close bond between sexual and aggressive drives has been obtained by Barclay (1971), who observed that the arousal of one of these motives is generally associated with increments in the other. Apparently, then sexual and agressive drives are indeed closely linked.

But what of the effect of heightened sexual arousal on

*Requests for reprints should be sent to the author, Department of Psychological Sciences, Purdue University, West Lafayette, Indiana 47907. The author wishes to express his sincere appreciation to Paul Bell for his aid in performing the statistical analyses, and to Pam Geick, Ed Gurausaks, Julie Nilson, and Pete Shepard for their able assistance in collection of the data. overt aggressive behavior? Are sexually aroused individuals actually more likely to engage in subsequent attacks against others than individuals not so aroused? The view that heightened emotional arousal, whatever its source, often facilitates overt aggression suggests that this will in fact be the case (see, e.g., Bandura, 1973). However, the results of two recent experiments conducted by the author (Baron, 1974; Baron \& Bell, 1973) indicate that opposite effects may actually be observed. More specifically, it was found in both of these investigations that moderate levels of sexual arousal (induced through exposure to Playboy nudes), led to significant reductions in the level of aggression demonstrated by angry male Ss.

The present experiment was designed to extend this previous work by determining whether levels of sexual arousal even milder than those induced among Ss in the Baron (1974) and Baron and Bell (1973) studies, would also be successful in producing such effects. More specifically, it sought to determine whether exposure to 
the type of erotic stimuli most frequently encountered in American society-a type often described as "cheesecake"-would also exert an inhibiting influence upon overt physical aggression. Such stimuli are extremely common in magazines, newspapers, television commercials, and other media offerings. Indeed, it is almost impossible for an individual to avoid exposure to some materials of this type on a daily basis. In view of this fact, it seemed important to examine the possibility that even the very mild levels of sexual arousal presumably induced by observation of such stimuli would tend to inhibit subsequent attacks against other human beings. In accordance with the findings of the Baron (1974) and Baron and Bell (1973) studies, it was tentatively predicted that this would indeed be the case. More specifically, it was expected that exposure to either "cheesecake" or the type of erotic stimuli employed in these earlier experiments (i.e., Playboy nudes) would tend to reduce the level of physical aggression evidenced by male Ss.

\section{METHOD}

\section{Subjects and Design}

Thirty-six undergraduate males enrolled in courses at Purdue University participated in the experiment. Ss were recruited as volunteers by the members of an undergraduate psychology class, under the restriction that they have had no psychology beyond the introductory course

A 3 by 2 factorial design, based upon three levels of sexual arousal (nonarousal, mild arousal, moderate arousal) and two levels of prior provocation (nonangry, angry) was employed. Ss were randomly assigned to each of the cells of this design as they appeared for their appointments.

\section{Apparatus}

The apparatus consisted of a modified "aggression machine" (Buss, 1961) identical to that employed in several previous studies (e.g., Baron, 1972, 1974), and a Lafayette stop clock (Model 54015).

\section{Procedure}

Anger Arousal. When Ss arrived for the experiment, they found a male confederate already seated in the waiting room. Shortly thereafter, the $\mathrm{E}$ arrived and conducted both individuals to another room where she explained that the first part of the study would be concerned with the manner in which individuals form first impressions of others. During this phase of the experiment, both the $\mathrm{S}$ and confederate were asked to write brief sketches or descriptions of their own personalities. These sketches were then ostensibly exchanged, and on the basis of this information, both individuals were asked to rate their partner of a series of traits (e.g., intelligence, maturity, sincerity). Finally, these ratings, too, were exchanged, so that both were able to learn what kind of impression they had made on their partner. In reality, of course, both the personality sketch and ratings Ss received from this individual were provided by the $\mathrm{E}$, and were varied in a systematic manner so as to influence their level of anger toward the future victim. Thus, in the nonangry condition, the personality sketch supposedly written by the confederate suggested that he was a pleasant, modest, and friendly individual. Moreover, the ratings he assigned to the $S$ were quite favorable and complimentary (e.g., he rated him as high in intelligence, maturity, likeableness, etc.). In contrast, in the angry group, the confederate's personality sketch suggested that he was an obnoxious, hostile, and conceited person. Further, his ratings of the $\mathrm{S}$ were highly unfavorable and quite derogatory.

Aggression Opportunity and Exposure to Erotic Stimuli. Following the completion of the above procedures, the $\mathrm{E}$ conducted the confederate and the $\mathrm{S}$ to an additional room where she explained that the second part of the study would be concerned with the effects of electric shock on physiological reactions (see Baron \& Eggleston, 1972). The $S$ was then assigned the task of delivering a series of shocks to the confederate, who was conducted to a third room by the $\mathrm{E}$, presumably so that the shock and physiological recording electrodes could be attached to his arms. After completing these procedures, the $\mathrm{E}$ returned to the room where the $\mathrm{S}$ was waiting and indicated that before beginning the shock trials, it would be necessary to wait for the confederate's physiological reactions to return to base levels. She further indicated that since this time was available, the $S$ would be asked to examine and rate a series of stimuli which might be used in a future study. In the nonaroused condition, these stimuli consisted of 10 pictures of scenery, furniture, and abstract paintings found in previous research, to be completely nonarousing (Baron, 1974). In the mild arousal (i.e., "cheesecake") condition, they consisted of 10 pictures of attractive young women in various states of undress. The scenes employed were taken from advertisements found in many different magazines, catalogs for large department stores, and the wrappers of pantyhose, brassieres, and other feminine garments. All were of the type which might be encountered in a casual inspection of virtually any popular magazine, a stroll down the aisles of any large department store, or examination of typical mail-order catalogs. Finally, in the moderate arousal condition, these stimuli consisted of 10 pictures of attractive, nude young women taken from back issues of Playboy magazine and found, in previous research, to be quite sexually arousing. In all three conditions, each stimulus was projected onto a screen directly in front of $\mathrm{Ss}$ by means of a Kodak Carousel slide projector (Model 800) for a period of $15 \mathrm{sec}$. Following presentation of the appropriate stimuli, the shock trials proceeded and Ss were provided with 20 opportunities on which to aggress against the confederate.

\section{RESULTS}

\section{Check on the Manipulation of Sexual Arousal}

In order to determine whether the three types of stimuli employed elicited different levels of sexual arousal among Ss, an analysis of variance was performed upon their ratings of these stimuli along the dimension "not arousing-very arousing." The results of this analysis indicated that the three types of stimuli differed significantly in terms of their arousing properties $(F=$ $5.69, \mathrm{df}=2 / 30, \mathrm{p}<.01)$. Follow-up comparisons between the means for the three groups by test indicated that $S s$ rated the nudes $(M=4.70)$ as significantly more arousing $(p<.05)$ than either the "cheesecake" $(M=3.40)$ or neutral $(M=3.22)$ pictures. Thus, it appeared that as anticipated, exposure to the "cheesecake" pictures elicited only minimal increments in sexual arousal among Ss, while exposure to the nudes induced somewhat greater increments in such arousal.

\section{Shock Duration and Intensity}

The mean durations of the shocks delivered to the confederate by Ss in each of the six experimental groups are represented in Table 1 . Inspection of this table reveals two findings of interest. First, as expected, Ss in the angry condition seemed to deliver somewhat longer 
Table 1

Mean Duration of Shocks Employed by Subjects in Each of Six Experimental Groups

\begin{tabular}{|c|c|c|c|}
\hline \multirow[b]{2}{*}{ Anger } & \multicolumn{3}{|c|}{ Degree of Sexual Arousal } \\
\hline & Nonaroused & Mild & Moderate \\
\hline Nonangry & .60 & .37 & .38 \\
\hline Angry & .63 & .50 & .43 \\
\hline
\end{tabular}

shocks to the confederate than those in the nonangry group. Second, and of somewhat greater interest, exposure to both types of erotic stimuli (i.e., "cheesecake" or nudes) seemed to reduce the duration of the shocks employed. An analysis of variance performed upon the data represented in Table 1 yielded a significant main effect for sexual arousal $(F=3.71, \mathrm{df}$ $=2 / 30, p<.05)$. Follow-up comparisons between the means of the nonaroused, mildly aroused, and moderately aroused groups by $t$ test indicated that those of the mild $(M=.43)$ and moderate $(M=.40)$ groups were significantly shorter $(p<.05)$ than that of the nonaroused group $(M=.61)$. Thus, it appeared that as predicted, exposure to both types of erotic stimuli tended to inhibit subsequent attacks against the victim. Despite the pattern of findings shown in Table 1, however, the main effect of anger arousal $(\mathrm{F}=1.09, \mathrm{df}=$ $2 / 30, \quad p>.20$ ) failed to attain significance. The procedures employed to vary this factor, therefore, were somewhat less effective than has been the case in previous investigations.

Somewhat surprisingly, results obtained with shock intensity failed to replicate those for shock duration. Although there was a tendency for sexual arousal (induced through exposure to both types of erotic stimuli) to inhibit aggression, and for angry Ss to direct stronger attacks against the confederate than nonangry Ss, neither of these effects proved to be significant. Apparently, then, mild increments in sexual arousal were effective in reducing the duration but not the magnitude of Ss' attacks against the confederate.

\section{DISCUSSION}

The hypothesis that aggression would be reduced by minimal as well as moderate levels of sexual arousal was confirmed. More specifically, Ss exposed to "cheesecake" and those exposed to nudes directed shocks of significantly shorter duration against the confederate than those who observed only neutral pictures of scenery, furniture, or art. The finding that even such minimal levels of sexual arousal were effective in reducing subsequent aggression appears to have potentially important implications. Thus, one possible explanation for its occurrence will now be proposed.

This explanation is suggested by two additional findings of the present study. First, Ss exposed to both types of erotic stimuli reported experiencing significantly more positive affect while examining these pictures than those exposed to the neutral, nonarousing scenes $(p<.05)$. Second, comments made by $S s$ in both of these groups during a brief postexperimental interview indicated that they found the mild sexual arousal they experienced to be quite pleasant. Combining these findings, it seems reasonable to suggest that these positive affective reactions proved to be somewhat incompatible with feelings of irritation toward the confederate or overt attacks against him, and so tended to reduce the level of aggression shown by Ss. This possibility is supported by the findings of several previous experiments (e.g., Berkowitz, Lepinski, \& Angulo, 1969) which suggest that aggression may be sharply inhibited by the arousal of responses or emotional states incompatible with such behavior. Additional evidence concerning the accuracy of such an interpretation may be readily obtained in future investigations by (1) assessing $\mathrm{Ss}^{\prime}$ affective states at several different points during the experiment, and (2) employing erotic stimuli which have been prescaled in terms of their ability to induce varying degrees of positive affect among Ss.

Although the finding that aggression was reduced by mild as well as moderate degrees of sexual arousal both supports and extends the results of previous experiments conducted by the author (Baron, 1974; Baron \& Bell, 1973), it contradicts the findings of other investigations which have reported that heightened sexual arousal may sometimes serve to enhance such behavior (e.g., Meyer, 1972; Zillman, 1971). One possible explanation for these contrasting results may lie in the fact that Ss in these previous studies were exposed to a type of erotic stimuli which caused them to experience relatively high levels of sexual arousal (films of attractive young couples engaged in active lovemaking). Because they could then do very little to bring about an immediate reduction in such arousal, they may have come to feel irritated, frustrated, or annoyed, and so directed stronger attacks against the victim than individuals not similarly aroused. In contrast, Ss in the present study actually seemed to enjoy the mild sexual arousal they experienced, and so (as noted above), may have lowered their level of attacks against the victim. In short, it is suggested that the impact of heightened sexual arousal upon subsequent aggression may depend, to an.important degree, upon the magnitude of such arousal. When it is very high and cannot be immediately reduced, it may be irritating or annoying, and so lead to enhanced aggression. When it is relatively mild, however, it may be pleasurable, and so actually serve to inhibit such behavior. The accuracy of these suggestions may be examined in future investigations by varying the level of sexual arousal experienced by Ss over a wider range of values than was the case in the present study.

\section{REFERENCES}

Bandura, A. Aggression: A social learning analysis. Englewood Cliffs, New Jersey: Prentice-Hall, 1973.

Barclay, A. M. Linking sexual and aggressive motives: Contributions of "irrelevant" arousals. Journal of Personality, 1971, 39, 481-492.

Baron, R. A. Aggression as a function of ambient temperature and prior anger arousal. Journal of Personality \& Social Psychology, 1972, 21, 183-189.

Baron, R. A. The aggression-inhibiting influence of heightened sexual arousal. Journal of Personality \& Social Psychology, 1974 , in press.

Baron, R. A., \& Bell, P. A. Effects of heightened sexual arousal on physical aggression. Proceedings, 81 st Annual Convention, APA, 1973, 171-172.

Baron, R. A., \& Eggleston, R. J. Performance on the "aggression machine": Motivation to help or harm? Psychonomic Science, 1972, 26, 321-322.

Berk owitz, L., Lepinski, H. P., \& Angulo, E. J. Awareness of own anger level and subsequent aggression. Journal of Personality \& Social Psychology, 1969, 11, 293-300.

Berne, E. Games people play. New York: Grove Press, 1964.

Buss, A. H. The psychology of aggression. New York: Wiley, 1961.

Freud, S. New introductory lectures on psycho-analysis. New York: Norton, 1933.

Meyer, T. P. The effects of sexually arousing and violent films on aggressive behavior. Journal of Sex Research, 1972, 8, 324-333.

Zillman, D. Excitation transfer in communication-mediated aggressive behavior. Journal of Experimental Social Psychology, 1971, 7, 419-434.

(Received for publication January 28, 1974.) 